From the SelectedWorks of Richard James

June 11, 2016

\title{
MEDLIB-L: March 2011-March 2016
}

Richard James

Linda Paulls

Helen-Ann Brown Epstein

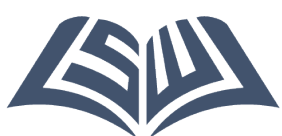

Available at: https://works.bepress.com/richard_james/6/

\section{SELECTEDWORKS ${ }^{\text {IM }}$}




\section{MEDLIB-L: March 2011 - March 2016}

RICHARD JAMES

Library, Philadelphia College of Osteopathic Medicine, Philadelphia, Pennsylvania, USA Volunteer MEDLIB-L Coordinator, Medical Library Association, Chicago, Illinois, USA

\section{LINDA PAULLS}

Seymour J. Phillips Health Sciences Library, Mount Sinai Beth Israel, New York, New York, USA

HELEN-ANN BROWN EPSTEIN

Health Sciences Library, Virtua, Mt. Laurel, New Jersey, USA

Nancy Start on January 23, 1991 founded MEDLIB-L, an email discussion list managed by the Medical Library Association for Health Information Professionals. It continues today to be an online gathering space for reference questions, help with difficult search strategies, placing and filling interlibrary loan requests, posting job vacancies, noting appreciation of good advice and weaving threads of conversations. This paper analyzes the demographics and contents of MEDLIB-L archives from March 2011 - March 2016. The data truly captures a snapshot of the daily "goings on" of a medical librarian. KEYWORDS listserv, discussion list, MEDLIB-L

\section{INTRODUCTION}

An old African proverb states it takes a village to raise a child. Hillary Rodham Clinton titled her book, It Takes a Village describing how to help make a society into the kind of village that enables children to become smart, able, resilient adults. On January 23, 1991, Nancy Start introduced MEDLIB-L into the Health Information Professional village and since then this unmoderated email discussion list is the method by which Medical Librarians communicate to improve health. This paper describes the demographics and 
contents of MEDLIB-L archives from March 2011 - March 2016 especially noting the number of reference questions, requests for help in formulating search strategies, meeting announcements, deadlines for awards and meeting registrations, interlibrary loan requests and how quickly they are filled, job postings, thank yous and interesting threads of conversations.

\section{HISTORY AND RULES}

Nancy Start founded MEDLIB-L on January 23, 1991. List ownership was transferred to the Medical Library Association on August 16, 1995. After being hosted at the University of Buffalo for many years, the list was transferred to the University of Vermont in May 2007. MEDLIB-L is a public, not moderated list and provides a forum for MLA members and other Health Sciences Information Professionals to discuss issues important to running their libraries and their profession. Posts to MEDLIB-L are not reviewed or censored before they appear. This means that some errors or inappropriate posts will occasionally appear on the list and some people will make mistakes. MLA accepts no responsibility for the opinions and information posted by users.

A volunteer MEDLIB-L Coordinator does handle education and policy issues for the list, which includes the proper way to post instructional messages, helping subscribers make best use of the medium, and responding to questions about what is appropriate to post. Since its inception, MEDLIB-L has had 8 Coordinators: Nancy Start, 1991-10/30/1995, Jan Mixter, 11/1/1995-10/31/1998, Gilliam Goldsmith Mayman, 11/1/1998- 09/30/1999, Valerie Rankow, 10/1/1999-10/30-2005, Mary Piorun, 11/1/2005-9/30/2008, Christine F. Marton, 10/1/2008-8/31/2012, and Judith Mills, 
10/01/2012-9/30/2015. Richard James is the current Coordinator and a contributing author of this article.

MLA accepts no responsibility for the opinions and information posted by users. It does reserve the right to moderate or cancel a user's subscription if the user does not abide by the MEDLIB-L guidelines. The MEDLIB-L Coordinator in consultation with other list members and MLA headquarters staff makes this decision. Guidelines at www.mlanet.org/p/cm/ld/fid=377, remind subscribers that MEDLIB-L is used for messages of professional interest to health sciences and/or medical librarians and information professionals.

It is not used for questions from the general public or medical personnel, for advertisements, for posting “job wanted” messages, for posting jobs for medical personnel, for posting duplicates or want lists, for general advocacy postings, or for virus, worm or hoax warnings. After having exhausted all local resources, reference questions can be posted to MEDLIB-L preceded by "Ref Q:" or "??". Answers should precede the subject with an exclamation point: “!”. Interlibrary loan requests should be for emergencies or if the title is unavailable through regular interlibrary loan networks. All copyright regulations must be observed. If a subscriber is asking for assistance in verifying a citation, the request should be preceded with "VERIF". Job postings should include the position title and geographic location. CHAT should precede entertaining messages. Sending individual private thanks is encouraged, but a message preceded by THANKS can be sent.

Posting rules include that posts go to the entire list, not selected individuals, and 
that posts should be precise, to the point and not a duplicate of an already posted item. A full signature is required at the end of the post. A new message should be created to reply. If one posts a question, the person agrees to summarize the responses in one post. As for copyright, all messages that appear are the property of the posting authors. Messages appearing on MEDLIB-L may be forwarded to other lists or individuals only with permission of the author of the post. Permission from the owner of copyrighted material must be obtained before posting. All this information is available on the Medical Library Associations website, MLAnet.org at http://www.mlanet.org/p/cm/ld/fid=377.

\section{DEMOGRAPHICS}

At the close of its first year, 1991, the MEDLIB-L listserv had 604 subscribers. By end of 1993, there were 1,821 subscribing addresses, which reflect even more participants, because some addresses served multiple readers. Although it is located in the United

States, subscribership is international, with participants from thirty-five countries.

MEDLIB-L experienced rapid growth in the first five years of its existence, and in 1997 had about 2,700 subscribers. In 2016, MEDLIB-L has 1970 subscribers. (See

Table 1) The number of international subscribers to the listserv in 2016 is down 18\% from 1995 with only 3\% being from non-English speaking countries, and only 11 subscribers in total being from countries in the "global south." See Figure 1 for MEDLIB-L's international membership distribution.

\begin{tabular}{|c|c|}
\hline Subscribers: 1970 & \\
\hline Subscribed under personal email addresses: 311 & \\
\hline & $17 \%$ \\
\hline Vendors and commercial subscribers & \\
\hline$\sim 100$ Subscriptions including & $5 \%$ \\
\hline 5 legal firms & \\
\hline
\end{tabular}




\begin{tabular}{|l|l|}
\hline 20 commercial subscribers & \\
\hline 70 vendors and publishers- representing 35 companies & \\
\hline U.S. Healthcare orgs and hospitals: & $23 \%$ \\
\hline 460 subscribers in $~ 300$ organizations & \\
\hline & $35 \%$ \\
\hline $\begin{array}{l}\text { U.S. Education domains (includes University Hospitals and Medical } \\
\text { Schools) }\end{array}$ & \\
\hline 700 Subscribers in 350 organizations & \\
\hline Non-US subscribers (all organization types) & $12 \%$ \\
\hline$\sim 250$ subscribers in 37 countries (12\%) & \\
\hline $90+$ Canadian & \\
\hline 55 European (20 British) & \\
\hline 35 Australian/NZ & \\
\hline 25 Middle Eastern & \\
\hline 10 Central/South American & \\
\hline 1 African & \\
\hline
\end{tabular}

Table 1. Demographics of MEDLIB-L 2016.

Figure 1 Geographic distribution of international MEDLIB-L subscribers 
While there are no point in time surveys from 1997-2016, it is notable that more than $80 \%$ of current subscriptions to MEDLIB-L were initiated within the past 5 years- well within the timeframe in which Facebook, Twitter and other social media has become ubiquitous and in which the 'death of email' has been announced fairly regularly. Clearly, professionals within the U.S. health and education domain have made an affirmative technology choice in favor of which people feel listserv is still essentially a legacy technology.

In 1997, Schoch and Shooshan published in the Bulletin of the Medical Library Association, the results of their electronically distributed survey conducted to determine demographic characteristics and uses of MEDLIB-L (1). They had 128 replies, or 38\% return. Subscribers predominantly $(81.1 \%)$ came from the United States with $6.3 \%$ from Canada, 2.4\% from Australia, 1.6\% from Great Britain and 7.9\% from other countries around the globe. Most subscribers worked at an academic institution (45\%), hospital (19\%), or other kind of library (13.5\%) with $44.4 \%$ workplaces having more than 5 professional staff, $35.7 \%$ with one to 5 staff and $20.4 \%$ were the only employee. Almost $7 / 8$ of the people that answered the survey were professionals. More than half of those were Medical Librarians for ten years or more.

\section{CONTENT ANALYSIS MARCH 2011-MARCH 2016}

The authors of this paper counted from the MEDLIB-L weekly lists, combined them into monthly totals and then into an annual total. See Table 2 below. Reference questions, searching tips, and meeting announcements were grouped under reference. Job postings were counted. When thanks were mentioned, it was also counted. 
Although, there are rules for posting different kinds of items to MEDLIB-L, they are not always followed. An interlibrary loan was filled, received or supplied. A job posting was a job posting, but also a job opportunity. Not all reference questions started with REF Q.

\begin{tabular}{|l|c|c|c|c|c|c|}
\hline \multicolumn{7}{|c|}{ MEDL8-L Transactions March 2011 -March 2016 } \\
\hline $\begin{array}{l}\text { Date } \\
\text { Mec 2011- }\end{array}$ & $\begin{array}{l}\text { Interlibrary } \\
\text { Loans }\end{array}$ & $\begin{array}{l}\text { Interlibrary } \\
\text { loans Filled }\end{array}$ & Reference & Jobs & Threads & Thanks \\
\hline 2012 & 1733 & 519 & 1968 & 96 & 147 & 38 \\
\hline 2013 & 1798 & 828 & 2246 & 139 & 96 & 41 \\
\hline 2014 & 2189 & 1022 & 2219 & 206 & 115 & 24 \\
\hline 2015 & 2363 & 1062 & 2250 & 250 & 135 & 33 \\
\hline $\begin{array}{l}\text { Jan 2016- } \\
\text { Mar 2016 }\end{array}$ & 656 & 285 & 694 & 47 & 37 & 9 \\
\hline Totals & 9847 & 4324 & 11586 & 908 & 593 & 168 \\
\hline
\end{tabular}

Table 2. MEDLIB-L Transactions March 2011 - March 2016

Fridays usually had the fewest transactions. However, they still contained interlibrary loan requests. Holidays, like Thanksgiving in November and Christmas in December had fewer transactions. 2015 was the busiest year with most interlibrary loan requests, most filled requests, most reference questions, job postings, and threads. 2013 had the most thanks. Projecting out the numbers from the first three months of 2016, this will also be a most productive year for the email discussion list.

Fill times were calculated if the interlibrary request and then the posting that the request was filled were listed under each other. The authors had a sense that interlibrary 
loan requests were filled quickly. Table 3 shows fill times for 375 requests. There were a handful of requests filled from 3 to 7 minutes, almost half filled within 30 minutes. However, it took overnight to fill 53 requests.

The MEDLIB-L rule for interlibrary loan requests states that requests should be confined to emergencies. Every week there were postings for urgent interlibrary loan requests and second try attempts. It was noted that some urgent requests were filled in less than ten minutes. The fastest was filled in three minutes. The rule also states that MEDLIB-L should be used for interlibrary loans from titles unavailable through regular interlibrary loan networks, like DOCLINE. However, in threats and rants, users have claimed this is being abused.

Schoch and Shooshan in their survey in 1997 showed that most participants claimed to read $41 \%$ to $100 \%$ of the postings, while less than $20 \%$ claimed to read $91 \%$ to $100 \%$ of the postings, a finding that led the researchers to feel that most participants did not find the entire enterprise useful and are probably filtering messages that they believe to be most relevant or useful (1). See Table below taken from the Schoch and Shooshan paper. 


\section{Table 1}

Percent of MEDLIB-L subscribers indicating the frequency with which they participate in various types of communication on the listserv

\begin{tabular}{lcccc}
\hline & Never & $\begin{array}{c}\text { Less than } \\
\text { once per } \\
\text { month }\end{array}$ & $\begin{array}{c}\text { Once per } \\
\text { month to } \\
\text { once per } \\
\text { week }\end{array}$ & $\begin{array}{c}\text { More than } \\
\text { once per } \\
\text { week }\end{array}$ \\
\hline Ask questions & 41.5 & 56.1 & 1.6 & 0.8 \\
Answer questions & 20.6 & 68.5 & 9.5 & 1.6 \\
Initiate discussion & 75.0 & 24.1 & 0.9 & 0.0 \\
Reply to discussion & 50.4 & 42.9 & 6.7 & 0.0 \\
Post information & 58.1 & 39.3 & 2.6 & 0.0 \\
\hline
\end{tabular}

Author Linda Paulls, of this paper, a new solo hospital librarian, echoes this sentiment. She joined MEDLIB-L when she realized she had many questions about medical library "things" that might be best approached after she considered the experiences and expert opinions of her peers. She certainly did gain many useful tips by reading the posts, but she often felt overwhelmed by the weekly volume emails she was receiving. Sorting through topics, including spam was often more than she had time to manage and therefore at some point she left online MEDLIB-L and just trolled its archive for tasty tidbits. She would consider resubscribing to the list when the list is moderated and limits the abundance of interlibrary loan requests. Subscribers do have the option to receive a weekly digest of posts. Many have the posts go directly into a folder for later viewing. Perhaps this option is one Linda and other busy hospital librarians should consider.

One explanation for the abundance of interlibrary loan traffic is that the foreign 
subscribers, who do not have DOCLINE, or HINARI are using MEDLIB-L for all their interlibrary loan transactions. Titles of journals were not scrutinized for this content analysis, but in passing they were noted to be a mixture of core and "not held every day" titles predominantly in English with some foreign language.

Time to Fill an Interlibrary Loan Request

\begin{tabular}{|l|c|c|c|c|c|}
\hline Date & $0-30$ minutes & 30 min -1 hour & 1 hour -3 hour & 3 hour -9 hour & overnight \\
\hline $\begin{array}{l}\text { Mar 2011- } \\
\text { Dec 2011 }\end{array}$ & 26 & 11 & 7 & 4 & 5 \\
\hline 2012 & 28 & 12 & 10 & 8 & 6 \\
\hline 2013 & 35 & 12 & 20 & 6 & 14 \\
\hline 2014 & 36 & 11 & 7 & 9 & 5 \\
\hline 2015 & 38 & 10 & 11 & 4 & 10 \\
\hline $\begin{array}{l}\text { Jan 2016- } \\
\text { Mar 2016 }\end{array}$ & 10 & 2 & 1 & 0 & 3 \\
\hline Totals & 173 & 58 & 60 & 31 & 53 \\
\hline
\end{tabular}

Table 3. Time to Fill Interlibrary Loan Requests

Threads are an important active part of the MEDLIB-L daily conversation. They are a platform for chatting, ranting and venting about products and behaviors. They are a platform for levity, especially on a Friday. Users announced library closings, and paid tribute when a special person in the industry died. Questions were asked and summaries 
were posted. From March 2011-March 2016, 593 threads of 5 or more participants and summaries of more than 100 lines were tallied. Table 4 displays a sample of the threads that got a high number of participantion. As one can see, there is a variety of seriousness and levity. MEDLIB-L now includes Chats. Answers to questions are summarized. Long summaries are so noted.

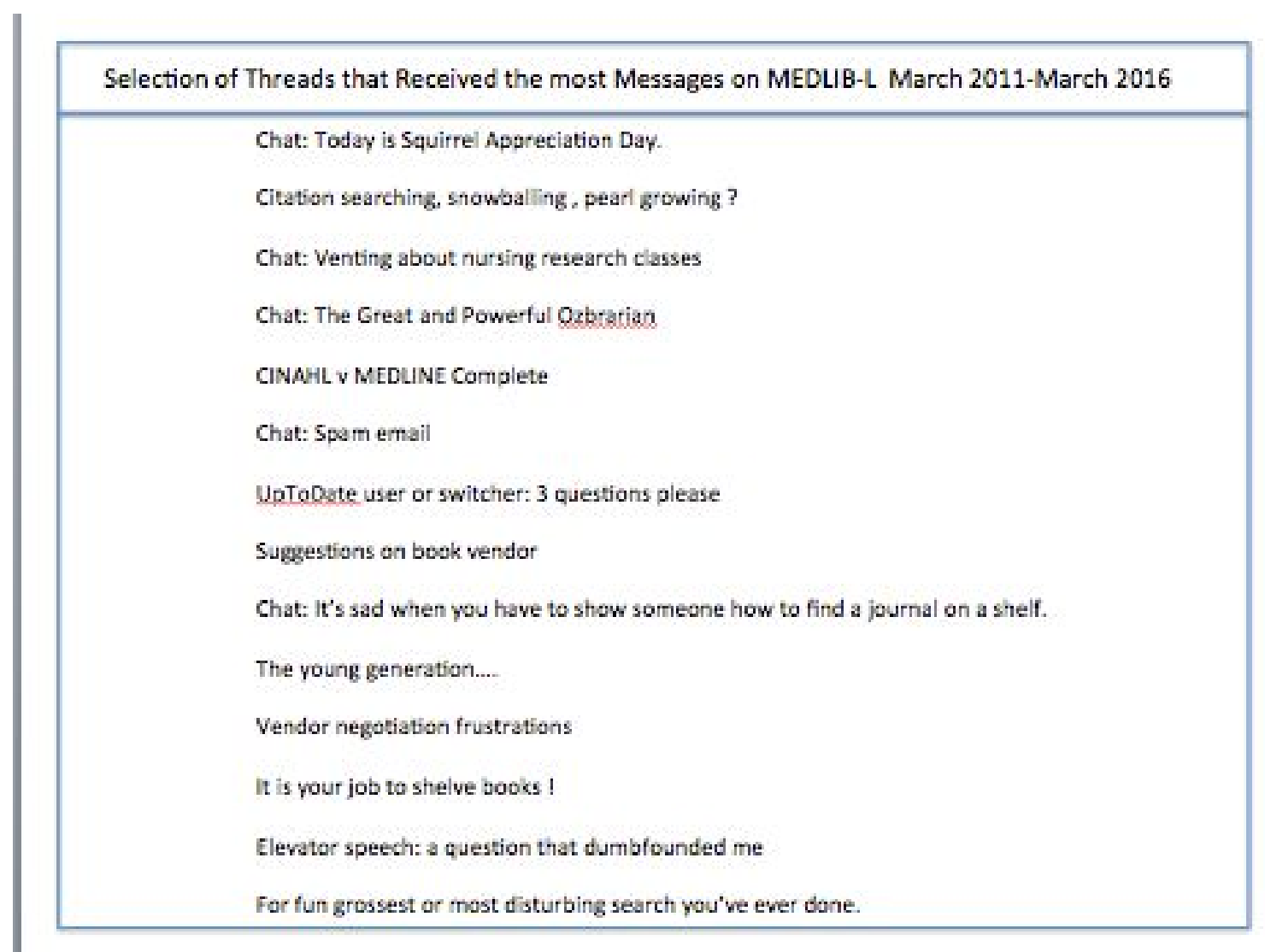

Table 4. Sample of threads that received most messages.

$$
\text { MEDLIB's FUTURE }
$$

MEDLIB-L's slow but not spectacular decline in total subscribers, along with the relative freshness of that subscriber base, suggests that this email discussion list will remain in operation for the foreseeable future, presuming the continuing goodwill 
of the Medical Library Association and the University of Vermont (UVM) to support the infrastructure.

However, it is unclear that UVM is likely to allocate much if anything in the way of support or development resources to listserv projects (2) and changes to spam filtering and other email platform features have created recent disruptions in services for many users (3) Richard James, the current MEDLIB-B coordinator and coauthor of this article feels it unlikely that any major email provider would factor in listserv accessibility to its development priorities, so there is a significant potential for future disruption that might adversely affect the usability and affordance of communication in this format.

While re-platforming the service might be preventative, the 'open-ness' of MEDLIB-L and listserv technology in general is highly valued in the library profession at large. Low barriers to entry, both technically and financially, ensure that professionals can participate whether or not their employers or personal circumstances provide for membership of organizations, and the sharing of information and advice within the profession internationally is a significant asset to medical librarianship in practice and philosophy. The Philadelphia Chapter of the Special Libraries Association recently attempted to restrict its mailing list communication to members only, which resulted in significant pushback from chapter members opposed to the decision for similar reasons.

As Coordinator of the listserv, this author would prefer not to have MEDLIB-L go gentle into that good night. While educating subscribers on how to 
gain the maximum convenience out of the service will continue to be ongoing. Former Coordinator, Valerie Rankow, often privately offlist reminded subscribers to close posts with full signatures and abide by other rules. James also is seeking to identify hacks and tips that will add value to users with particular needs. For instance, work on identifying ways to create an "ILL-less" digest using the IFTTT.com web alert service is underway.

As mentioned above, the number of international subscribers to the listserv is down from 18\% in 1995 with only 3\% being from non-English speaking countries, and only 11 subscribers in total being from countries in the "global south" (see figure 2) and none from countries eligible for low- or no-cost access to HINARI. This being the case, opportunities must exist to promote MEDLIB-L as a legal, low/no cost opportunity for medical librarians in the developing world.

Also as demonstrated above, the goodwill of most subscribers concerning resource sharing is tremendous, and is used to satisfy unmet needs both domestically in the United States and with librarians abroad who lack access to resources the U.S. profession takes for granted. As access to resources has become somewhat of an claimed issue of academic justice, and as it has become easier for resource-challenged researchers to access scholarly literature through Sci-Hub and other illegal file sharing sites, an expansion of MEDLIB-L into the "global south" and enhanced support of non-English speaking subscribers may be a natural extension of the principles supporting this service in a way which serves a broader ideal. 
MEDLIB-L with its place as an online forum for interlibrary loan requests, asking and giving advice, answering reference questions, posting job openings and a place for chatting, ranting and instilling a touch of levity, continues to be a daily fixture in the workings of a hospital librarian. This 5 year content analysis reveals an active global platform for improving health.

\section{REFERENCES}

1. Schoch NA. , Shooshan SE. Communication on a listserv for health information professionals: uses and users of MEDLIB-L. Bull Med Libr 1997 Jan;85(1):23-32. 2. James, R. Personal Conversation with University of Vermont Help Desk, March 2016.

3. Problems with MEDLIB and Gmail. MEDLIB-L Archives listserv discussion. April 5, 2016. https://list.uvm.edu/cgi-bin/wa?A2=MEDLIB-L;53ad5b65.1604A. (23 Apr 2016). 